\title{
NUTRITIONAL AND MATERNAL FACTORS INFLUENCING POSTPARTUM HAEMORRHAGE IN LAMBUSSIE DISTRICT
}

\author{
Taabia $^{1,4}$, F. Z., Mornah ${ }^{2,4}$, L. N. \& ${ }^{3}$ Wombeogo, M. \\ ${ }^{1}$ Lambussie District Health Directorate, Ghana Health Service, Box 6, Upper West Region, Ghana \\ ${ }^{3}$ Lawra Municipal Hospital, Ghana Health Service, Box 19, Upper West Region, Ghana \\ ${ }^{3}$ KAAF University College, School of Nursing and Midwifery, Box WU 177, Gomoa East, C/R. Ghana \\ ${ }^{4}$ Department of Public Health, University for Development Studies, Box TL 1884, Tamale, Ghana
}

\begin{abstract}
Maternal excessive bleeding at birth continues to be a global public health challenge, particularly in poor resource settings. Postpartum haemorrhage has been linked to a high proportion of maternal deaths and disabilities at the institutional and community levels. Current data on postpartum haemorrhage is limited to institutional settings and does not consider the community experiences of mothers who suffer from postpartum haemorrhage. This cross-sectional study assessed the nutritional and other maternal risk factors associated with postpartum haemorrhage at the community level. A total of 183 mothers were systematically sampled from six sub-districts. Data was analyzed using SPSS version 22.0. Multivariate logistic and regression models were estimated to assess the association between dependent and independent variables at a confident level of 95\%. The results from the study showed that the prevalence of postpartum haemorrhage was $7.1 \%$ among the mothers interviewed in the study. Age groups $(p<0.001)$ of mothers influenced postpartum haemorrhage as experienced by some mothers during delivery, and also maternal height ( $p<0.001)$, Iron-folic acid (IFA) daily supplements ( $p<0.020)$, Gravidity $(p<0.001)$, anaemia $(p<0.001)$ and malnutrition at 36 weeks of pregnancy $(p<0.008)$. Although the prevalence of postpartum haemorrhage is relatively minor, the effects of poor nutrition on excessive maternal bleeding cannot be underestimated. Improving maternal nutritional status could reduce the chances of bleeding during delivery and possibly improve all birth outcomes. Policymakers need to develop nutrition-specific interventions for mothers before and during pregnancy.
\end{abstract}

\section{Keywords: Postpartum, Haemorrhage, Maternal, Nutrition, Risk-Factors}

\section{Introduction}

Adequate maternal nutrition is generally recognized to play a critical role in promoting the health of both mothers and babies before and during pregnancy and after childbirth. The nutritional status of the mothers can further inform their health status during and after pregnancy, leading to both short and long-term effects (Cetin \& Laoreti, 2015; NICE, 2015). Poor maternal health and nutritional status have been related to adverse birth outcomes such as postpartum haemorrhage and maternal deaths, among others (Abu-Saad \& Fraser, 2010). However, the interrelationship between these maternal risk factors and birth outcomes is complex and may be influenced by several other factors such as socioeconomic, biological, and demographic 
factors. These may also vary widely among different populations (Abu-Saad \& Fraser, 2010). As cited by Mpemba et al. (2014), the previously known risk factors do not currently predict PPH, and almost 7 out of 10 cases of PPH do not have identifiable risk factors.

The complexity of the situation is also due partly because about half of all pregnancies are unplanned (NICE, 2015), and so, most women are not able to build their nutritional stores before conception, which also predispose them to some deficiencies in the face of the increased nutritional requirements due to the pregnancy. For example, anthropometric indicators such as gestational weight gain and body mass index before pregnancy play a significant role in the energy requirements during pregnancy (WHO, 2016; Cetin \& Laoreti, 2015). These nutritional status indicators also predict maternal health outcomes, both short-and-long-term. Therefore, it is recommended that improved GWG and pre-pregnancy BMI are necessary to reduce adverse pregnancy outcomes (Cetin \& Laoreti, 2015).

Haemorrhage (PPH) is the leading cause of maternal mortality, contributing to one-third of maternal deaths globally (Ashigbie, 2013; Bonnet \& Benhamfou, 2016). According to Ashigbie (2013), although maternal deaths had decreased globally, developing countries record higher figures due to postpartum haemorrhage. $\mathrm{PPH}$ is defined as blood loss greater than $500 \mathrm{mls}$ and continuing. However, clinically significant PPH is more usefully defined as any excessive bleeding that causes the woman to become symptomatic (Oyelese \& Ananth, 2010). Globally, PPH is estimated to be $13.6 \%$, with Latin America and Asia reporting $8 \%, 13 \%$ in North America, and as high as $26 \%$ in Africa (Calvert, Thomas, Ronsmans, Wagner, Adler, and Filippi, 2012). In the subsequent year, a multi-country survey conducted by the World Health Organization reported a rate of $1.2 \% \mathrm{PPH}$ across 28 countries (Sheldon et al., 2013). Also, in the US, data showed that about $8 \%$ of the total maternal deaths resulted from PPH, between 2-6\% in India (Kumar, 2016), and an institutional prevalence of $15.8 \% \mathrm{PPH}$ in Ghana (Owiredu et al., 2016).

Then again, maternal anaemia in pregnancy has been found to predict adverse postpartum haemorrhage (Frass, 2015; Sheldon et al., 2013). According to Frass (2015), haemoglobin level of $<10 \mathrm{~g} / \mathrm{dl}$ increased women's risk of PPH up to almost 30 times. Owiredu et al. (2016) similarly found the $\mathrm{Hb}$ level of mothers to be significantly associated with their status of PPH during delivery. Maternal obesity is another nutritional factor found to be related to postpartum haemorrhage. According to Kumar (2016), a higher body mass index increases the risk of atonic uterine haemorrhage rapidly. BMI greater than $40 \mathrm{~kg} / \mathrm{m} 2$ increased the risk to $13.6 \%$ and $5.2 \%$ with instrumental and normal deliveries, respectively (Kumar, 2016). Also, with infants, foetal macrosomia $\geq 4000 \mathrm{~g}$ is reported to significantly increase PPH risk (Ononge et al., 2016).

Also, maternal factors such as age (Sheldon et al., 2013), multiple pregnancies (Mpembe et al., 2014; Ononge et al., 2016), and parity (Calvert et al., 2012; Sheldon et al., 2013; Cetin \& Laoreti, 2015; WHO, 2016) were related to some adverse birth outcomes including PPH. For instance, pregnant adolescent girls are still undergoing some growth at the time of conception, experiencing additional nutrient needs due to the developing foetus, thus predisposing them to undernutrition (Cetin \& Laoreti, 2015). Then again, institutional factors such as the mode of delivery (Calvert et al., 2012), lack of health facilities and trained health care providers (Der et al., 2013; Ononge et al., 2016; Calvert et al., 2012; Mpemba, Kampo \& Zhang, 2014).

According to Mpembe et al. (2014), the previously known traditional PPH risk factors do not significantly predict PPH. This is because some cases of PPH do not have identifiable risk factors (Mpembe et al., 2014), this necessitates the need to evaluate every pregnant woman for individual and other risk factors to offer prevention and early intervention as and when they do happen. For instance, the Northern part of Ghana is particularly known for higher maternal deaths, mainly due to 
postpartum haemorrhage (Program for Appropriate Technology in Health [PATH], 2014). Because there has been delayed progress to specifically prevent $\mathrm{PPH}$ at both the health facilities and community level, where births still do occur, and nearly half of pregnant women deliver at home, reinforcing the need for community-based measures to prevent PPH (PATH, 2014). There is, therefore, the need for community-grown preventive measures that seek to optimize maternal and nutritional factors to reduce the risk of PPH, even in resource-constraint settings.

Maternal nutrition is one of the cardinal measures that can influence birth outcomes and, it is against this background that the study sought to assess the maternal and nutritional risk factors influencing PPH to help improve the health status of rural women. Moreover, given the numerous consequences of PPH on the quality of life, it is of great importance to identify factors contributing to PPH and hence understand the relation between maternal risk factors and $\mathrm{PPH}$, which would provide the basis for developing maternal sensitivity and specific interventions that will improve birth outcomes and long-term quality of life and reduce disease occurrence, deaths, and hospital stay and health-care costs, even among the rural women in remote places like Lambussie. This study sought to provide local-level information on the prevalence of these PPH and its associated maternal factors in the Lambussie District.

\section{Materials and Methods}

\section{Study Site and Design}

The study was a facility-based cross-sectional survey covering 25 public health facilities in Lambussie, a district in Ghana. Lambussie is one of the 11 districts in the Upper West Region. The study covered the six sub-districts in the Lambussie district. These sub-districts comprised five health centres, one polyclinic, and nineteen CHPS zones. These sub-districts were evenly sampled to represent a mix of Dagaaba, Moshi, and Sissala Communities, peri-urban and rural populations, therefore ensuring that the distribution in social groups of the study population was assumed to be similar to the entire population of the District. The study population consisted of all lactating mothers aged 15 to 49 years. However, only women who deliver at the required health facility and by a midwife, community health officers, medical officer, or physician assistant were included in the study to measure the outcome variables.

A total of 190 lactating mothers receiving postnatal and child welfare services with babies less than 90 days old were sampled for the study. It was assumed that lactating mothers of a shorter delivery duration (maximum of three months) before the study were more likely to recount their recent experiences in the pregnancies to meet the purpose of the study. The study categorized the District into strata (sub-districts), and each stratum was assigned a proportion (quota) of the sample size regarding the projected population for that particular stratum. Therefore, a sampling interval was obtained for each specific stratum depending on the quota of the sample size assigned to that stratum.

A structured questionnaire was used in collecting quantitative data from respondents by a team of trained community health officers/midwives. Information on maternal postpartum haemorrhage (PPH) status was obtained from the maternal health record booklets given to the mothers. Mothers' PPH status was assessed as the primary dependent variable. Mothers who delivered at home or by unskilled attendants were excluded from the study because mothers or unskilled attendants could not estimate the quantity of blood loss accurately. Other secondary data were extracted from the maternal health record booklets, including ANC services, IFA supplementation, HB testing \& counselling, maternal illnesses, pre-existing maternal condition, and the frequency of visits to the health facilities.

Primary data was obtained directly from the respondents on the socio-demographic, socioeconomic, and dietary history. Maternal diet history and socioeconomic data such as education level, marital status, household wealth index, 
occupation of caregivers also served as the independent variables. In all, 183 copies of a questionnaire were fully completed by the respondents representing a $96.3 \%$ response rate.

\section{Data Analysis}

The data was analyzed using SPSS version 22.0. Descriptive statistics included means and standard deviations for continuous variables and frequency distributions and proportions for the categorical variables. Bivariate analyses were done using chisquare statistics to determine the associations between categorical variables with statistical significance set at $\mathrm{p}<0.05$. Multivariate logistic regression models were used to determine the maternal and nutritional predictors of PPH among the study population. All respondents in the study were issued informed consent forms to seek their voluntary participation. Additionally, approval was also given from the District Health Directorate, while ethical clearance was obtained from the Navrongo Health Research Center (NHRCIRB299).

\section{Results}

\section{Socioeconomic Characteristics}

A total of 183 correctly answered copies of a questionnaire were entered for analysis. The results showed that the District was primarily rural, as $86.9 \%$ of the respondents were rural residents and $13.1 \%$ were urban residents. The youngest mother in the study was 15years old, the oldest was 44years, and the mean age of the respondents was $27.6 \pm 5.526 y$ rs. From the study results, the general prevalence of PPH (>500ml) was 7.1\% (13) among the mothers. The majority $(84.6 \%)$ of the PPH cases came from mothers in rural settings and mothers who underwent spontaneous virginal delivery $(92.3 \%)$. The study results showed that the Dagaara ethnic group contributed most of the PPH cases (Table 1). Mothers of Christian background contributed $69.2 \%$ of the PPH cases, and all the mothers who experienced PPH in the study were formally married or cohabitating with male partners (Table 1).

Table 1: Socioeconomic Characteristics of the Respondents

\begin{tabular}{|c|c|c|c|c|}
\hline Variables & Categories & $\mathbf{N \%}$ & РPH\% & P-value \\
\hline Age & Minimum (15yrs) & Maximum (44yrs) & \multicolumn{2}{|c|}{ Mean $(27.6 \pm 5.526 y r s$} \\
\hline \multirow[t]{3}{*}{ Age Groups of Mothers } & $<20$ years & $16(8.7 \%)$ & $1(7.7 \%)$ & 0.751 \\
\hline & 20-30years & $116(63.4 \%)$ & $7(53.8 \%)$ & \\
\hline & >30years & $51(27.9 \%)$ & $5(38.5 \%)$ & \\
\hline \multirow[t]{2}{*}{ Residential Status of mothers } & Rural Residents & $159(86.9 \%)$ & $11(84.6 \%)$ & 0.681 \\
\hline & Urban Residents & $24(13.1 \%)$ & $2(15.4 \%)$ & \\
\hline \multirow[t]{3}{*}{ Ethnicity } & Sissala & $51(27.9 \%)$ & $4(30.8 \%)$ & 0.931 \\
\hline & Dagaara & $111(60.7 \%)$ & $8(61.5 \%)$ & \\
\hline & Others & $21(11.5 \%)$ & $1(7.7 \%)$ & \\
\hline \multirow[t]{3}{*}{ Religion } & Christianity & $111(60.7 \%)$ & $9(69.2 \%)$ & 0.906 \\
\hline & Islam & $54(29.5 \%)$ & $3(23.1 \%)$ & \\
\hline & African Tradition & $18(9.8 \%)$ & $1(7.7 \%)$ & \\
\hline Education & No formal education & $82(44.8 \%)$ & $7(53.8 \%)$ & 0.827 \\
\hline
\end{tabular}




\begin{tabular}{|c|c|c|c|c|}
\hline & Primary education & $54(29.5 \%)$ & $4(30.8 \%)$ & \\
\hline & Secondary education & $35(19.1 \%)$ & $1(7.7 \%)$ & \\
\hline & Tertiary education & $12(6.6 \%)$ & $1(7.7 \%)$ & \\
\hline \multirow[t]{3}{*}{ Marital Status } & Single & $4(2.2 \%)$ & - & \\
\hline & Married/Cohabitation & $178(97.3 \%)$ & $13(100 \%)$ & \\
\hline & Separated/Divorced/Widowed & $1(0.5 \%)$ & - & \\
\hline \multirow[t]{2}{*}{ Alcohol Intake } & Yes & $101(55.2 \%)$ & $8(61.5 \%)$ & 0.775 \\
\hline & No & $82(44.8 \%)$ & $5(38.5 \%)$ & \\
\hline \multirow[t]{4}{*}{ Means of Transport to delivery } & Motorbike/Tricycle & $114(62.3 \%)$ & $9(69.2 \%)$ & 0.944 \\
\hline & Footing & $55(30.1 \%)$ & $3(23.1 \%)$ & \\
\hline & Lorry/Vehicle & $8(4.4 \%)$ & $1(7.7 \%)$ & \\
\hline & Bicycle & $6(3.3 \%)$ & - & \\
\hline \multirow[t]{4}{*}{ Occupation } & Farming & $132(72.1 \%)$ & $11(84.6 \%)$ & 0.443 \\
\hline & Petty Trading & $27(14.8 \%)$ & $1(7.7 \%)$ & \\
\hline & Formal Sector & $8(4.4 \%)$ & $1(7.7 \%)$ & \\
\hline & Housewives & $16(8.7 \%)$ & - & \\
\hline \multirow[t]{4}{*}{ HH Annual Net Income } & $<100.00 \mathrm{ghc}$ & $71(38.8 \%)$ & $4(30.8 \%)$ & 0.863 \\
\hline & $101.00-500.00 \mathrm{ghc}$ & $73(39.9 \%)$ & $5(38.5 \%)$ & \\
\hline & $501.00-1000.00 \mathrm{ghc}$ & $26(14.2 \%)$ & $3(23.1 \%)$ & \\
\hline & $>1000.00 \mathrm{ghc}$ & $13(7.1 \%)$ & $1(7.7 \%)$ & \\
\hline
\end{tabular}

Source: Field survey, (2018)

Also, mothers who used motorbikes/tricycles to their specific facilities for delivery accounted for $69.2 \%$ of the PPH cases. Then again, $7.7 \%$ were from vehicle users, while $33.1 \%$ of the cases came from mothers who walked on foot to the delivery facilities. Also, mothers exposed to alcohol during their pregnancy contributed $61.5 \%$ of the cases of $\mathrm{PPH}$, and those without alcohol exposure contributed $38.5 \%$. Farming mothers also accounted for $84.6 \%$ of the PPH cases, petty traders $7.7 \%$, and formal sector workers $7.7 \%$. Lastly, mother who earned an estimated household annual net income of $<100.00 \mathrm{ghc}$ accounted for $30.8 \%$ of the cases, 101.00-500.00ghc 38.5\%, $501.00-1000.00$ ghe $23.1 \%$ and $>1000.00$ ghc $7.7 \%$ (Table 1).

\section{Maternal and Institutional Factors and PPH}

On the categories of health facilities available to the respondents in the district, $45.4 \%$ of them delivered in a clinic/health centre, while $43.7 \%$ delivered in a polyclinic and $10.9 \%$ delivered in CHPS compounds. Concerning PPH and the type of health facility, $61.5 \%$ of the PPH cases were recorded in a polyclinic, $30.8 \%$ in health centres, and $7.7 \%$ in CHPS compounds. Also, primed mothers made up $25.1 \%$ of the sampled population and contributed to $30.8 \%$ of the PPH cases. The proportion of the mothers who went through spontaneous vaginal delivery (SVD) was $88 \%$, and 12\% delivered through Caesarean Session (Table 2). 
Table 2: Maternal and Institutional Factors of Respondents

\begin{tabular}{llccc}
\hline Variables & Categories & N\% & PPH\% & P-value \\
\hline Place of Delivery & CHPS Compound & $20(10.9 \%)$ & $1(7.7 \%)$ & 0.482 \\
& Clinical/Health Centre & $83(45.4 \%)$ & $4(30.8 \%)$ & \\
& Polyclinic/Hospital & $80(43.7 \%)$ & $8(61.5 \%)$ & \\
\hline Mode of Delivery & Caesarean Session & $22(12 \%)$ & $1(7.7 \%)$ & 0.519 \\
& Natural Virginal Delivery & $161(88.0 \%)$ & $12(92.3 \%)$ & \\
\hline Gravidity & first pregnancy & $46(25.1 \%)$ & $4(30.8 \%)$ & 0.599 \\
& 2-3rd pregnancy & $74(40.4 \%)$ & $4(30.8 \%)$ & \\
& 4-6th pregnancy & $58(31.7 \%)$ & $4(30.8 \%)$ & \\
& 7 \& above pregnancy & $5(2.7 \%)$ & $1(7.7 \%)$ & \\
\hline Parity & 1st child & $45(24.6 \%)$ & $4(30.8 \%)$ & 0.332 \\
& 2-3rd child & $80(43.7 \%)$ & $5(38.5 \%)$ & \\
& 4-6th child & $55(30.1 \%)$ & $3(23.1 \%)$ & \\
& >7th child & $3(1.6 \%)$ & $1(7.7 \%)$ & \\
\hline
\end{tabular}

\section{Nutritional Risk Factors and PPH}

Nutritional counselling routinely offered at the health facilities was given to $92.9 \%$ (170) respondents. Mothers who received this nutritional counselling contributed to $84.6 \%$ of the PPH cases. Mothers who took extra meals in addition to their normal food intake due to their pregnancy also presented $69.2 \%$ cases of $\mathrm{PPH}$, and $30.8 \%$ cases were from mothers who continued with only their everyday meals (Table 3). Dietary diversities also showed disparities in presenting the number of PPH cases. Respondents who ate from 2-3 food groups contributed $53.8 \%$ of the cases, and $46.2 \%$ cases came from those who ate $\geq 4$ food groups. Respondents who fully complied with iron-folic acid (IFA) supplementation presented with $69.2 \%$ cases of PPH; $30.8 \%$ came from mothers who partially or did not comply at all. Mothers who tabooed some food items presented with $30.8 \%$ of the cases. Upon registering their pregnancies with the health facilities, $80.3 \%$ of the mothers were of normal body mass index, while $8.7 \%, 8.2 \%$, and $2.7 \%$ were overweight, underweight and obese respectively, (Table 3). Also, during antenatal care registration, $52.5 \%$ of the mothers had lower $\mathrm{Hb}$ levels of $<11 \mathrm{~g} / \mathrm{dl}$. Subsequently, mothers with lower $\mathrm{Hb}$ at ANC registration and 36weeks of pregnancy accounted for $38.5 \%$ and $30.8 \%$ of the cases, respectively. Lastly, almost all the mothers did not obtain adequate gestational weight gain (GWG) during their pregnancy. These mothers presented with $92.3 \%$ of the cases, while the $2.7 \%$ who obtained excessive GWG also presented with $7.7 \%$ cases of the PPH (table 3 ).

Table 3: Nutritional factors and PPH Occurrence

\begin{tabular}{llccc}
\hline Variables & Categories & N\% & PPH\% & P-value \\
\hline Nutrition Counseling & No & $13(7.1 \%)$ & $2(15.4 \%)$ & 0.233 \\
& Yes & $170(92.9 \%)$ & $11(84.6 \%)$ & \\
\hline \multirow{2}{*}{ Extra Meal in Pregnancy } & NO & $44(24 \%)$ & $4(30.8 \%)$ & 0.737 \\
& Yes & $139(76 \%)$ & $9(69.2 \%)$ & \\
\hline Dietary Diversity & $2-3$ food groups & $101(55.2 \%)$ & $7(53.8 \%)$ &
\end{tabular}




\begin{tabular}{|c|c|c|c|c|}
\hline & $4 \&$ above food groups & $82(44.8 \%)$ & $6(46.2 \%)$ & \\
\hline \multirow[t]{3}{*}{ IFA Intake in pregnancy } & fully complied & $152(83.5 \%)$ & $9(69.2 \%)$ & 0.111 \\
\hline & Partially complied & $27(14.8 \%)$ & $3(23.1 \%)$ & \\
\hline & didn't comply & $3(1.6 \%)$ & $1(7.7 \%)$ & \\
\hline \multirow[t]{2}{*}{ Food taboos in pregnancy } & No & $139(76 \%)$ & $9(69.2 \%)$ & 0.737 \\
\hline & Yes & $44(24 \%)$ & $4(30.8 \%)$ & \\
\hline \multirow[t]{4}{*}{$\mathrm{BMI}$ categories at $\mathrm{ANC}$ registration } & Underweight & $15(8.2 \%)$ & $1(7.7 \%)$ & 0.201 \\
\hline & Normal weight & $147(80.3 \%)$ & $9(69.2 \%)$ & \\
\hline & Over-weight & $16(8.7 \%)$ & $3(23.1 \%)$ & \\
\hline & Obese & $5(2.7 \%)$ & - & \\
\hline \multirow[t]{3}{*}{ BMI at 36wks/delivery } & Normal weight & $121(66.1 \%)$ & $8(61.5 \%)$ & 0.698 \\
\hline & Over-weight & $54(29.5 \%)$ & $5(38.5 \%)$ & \\
\hline & Obese & $8(4.4 \%)$ & - & \\
\hline \multirow[t]{3}{*}{ Categories of the net change in GWG } & Low G.W. G & $169(92.3 \%)$ & $12(92.3 \%)$ & 0.305 \\
\hline & Adequate G.W.G. & $9(4.9 \%)$ & - & \\
\hline & Excessive G.W. G & $5(2.7 \%)$ & $1(7.7 \%)$ & \\
\hline \multirow[t]{2}{*}{$\mathrm{Hb}$ categories at $\mathrm{ANC}$ registration } & Anaemia & $96(52.5 \%)$ & $5(38.5 \%)$ & 0.390 \\
\hline & Normal $\mathrm{Hb}$ & $87(47.5 \%)$ & $8(61.5 \%)$ & \\
\hline \multirow[t]{2}{*}{$\mathrm{Hb}$ categories at $36 \mathrm{wks} /$ delivery } & Anaemia & $69(37.7 \%)$ & $4(30.8 \%)$ & 0.769 \\
\hline & Normal $\mathrm{Hb}$ & $114(62.3 \%)$ & $9(69.2 \%)$ & \\
\hline \multirow[t]{2}{*}{ BW of infants } & LBW & $15(8.2 \%)$ & $2(15.4 \%)$ & 0.605 \\
\hline & NBW & $168(91.8 \%)$ & $11(84.6 \%)$ & \\
\hline \multirow[t]{2}{*}{ Apgar score categories of infants } & Severe/moderate Asphyxia & $17(9.3 \%)$ & $2(15.4 \%)$ & 0.614 \\
\hline & Normal Apgar score & $166(90.7 \%)$ & $11(84.6 \%)$ & \\
\hline
\end{tabular}

Source: Field Survey, 2018

In a stepwise multiple regression modelling, individual factors such as the height of mothers $(\mathrm{p}<0.001)$ and mothers' age grouping $(\mathrm{P}<0.001)$ were significantly associated with maternal PPH at delivery. The height of mothers at delivery was a positive predictor of PPH during delivery, whereas the age grouping of the mothers had a negative effect on the PPH status of the mothers at the period of delivery.

Table 4: Maternal and Nutrition Factors Influencing PPH at Delivery

\begin{tabular}{lcccc}
\hline \multicolumn{1}{c}{ Models } & $\begin{array}{c}\text { Standardized } \\
\text { Coefficients }\end{array}$ & Sig. & \multicolumn{2}{c}{$\mathbf{9 5 . 0 \% \text { Confidence Interval }}$} \\
& Lower Bound & Upper Bound \\
\hline Height of Mothers & 5.873 & 0.001 & 0.016 & 0.034 \\
\hline Mothers' Age Categories & -4.873 & 0.001 & -0.4 & -0.164 \\
\hline IFA Intake & -2.459 & 0.020 & -0.271 & -0.025 \\
\hline
\end{tabular}




\begin{tabular}{lllll}
\hline Mothers' Hb at 36weeks/delivery & -3.572 & 0.001 & -0.123 & -0.033 \\
\hline BMI Categories at ANC Registration & 2.804 & 0.009 & 0.054 & 0.346 \\
\hline BMI Categories at 36weeks/delivery & -2.831 & 0.008 & -0.292 & -0.047 \\
\hline Gravidity & 3.536 & 0.001 & 0.055 & 0.205 \\
\hline Apgar score of Infant at Birth & 4.873 & 0.001 & 0.362 & 0.885 \\
\hline
\end{tabular}

Source: Field Survey, 2018

Gravidity of the mothers also showed a significant influence $(\mathrm{p}<0.001)$ on the status of PPH in the study (Table 4). IFA supplementation also showed a significant association $(p<0.02)$ with the mothers' PPH status at the time of delivery. In the current study, maternal supplementation showed a negative influence on the status of PPH at delivery. This indicated that a unit increase in the intake of IFA resulted in a 2.5 times likelihood decrease in their risk of PPH. Then again, anaemic mothers at 36weeks of pregnancy also showed a significant association with the status PPH at delivery. Body Mass Indices (BMI) of mothers at ANC registration $(\mathrm{p}<0.009)$ and at 36weeks of pregnancy $(\mathrm{p}<0.008)$ were also significant predictors of PPH among the study population. However, BMI is not an accurate indicator of nutrition status due to increased maternal tissues resulting from the pregnancy (table 4 ). Then again, a unit change in maternal $\mathrm{Hb}$ at 36 weeks of pregnancy had an equivalent reduction in risk of PPH by 3.6units. Lastly, the Apgar score $(\mathrm{p}<0.001)$ of the infants born to the mothers showed a significant association with the status of $\mathrm{PPH}$ of the mothers in the study (Table 4). However, additional meals in pregnancy, BW of infants, the net change in GWG, food taboos in pregnancy, dietary diversity, and nutrition counselling did not indicate any significant association with the status among mothers in the study.

\section{Discussion}

Maternal PPH (>500ml bleeding) at delivery among the study population in the Lambussie
District was $7.1 \%$. The low prevalence rate in the current study could be due to the small sample size and possibly because community-level or household deliveries were not catered for in this study. Similar prevalence rates were found in Uganda (9\%), Pakistan (7.4\%) (Ononge et al., 2016), and New Zealand (8.9\%) (Fyfe et al., 2012). Comparative to the prevalence rate contained in this study, a higher overall prevalence rate $(34 \%)$ was observed in Sub-Saharan Africa (Motsi, 2006), and some selected studies in African countries like 23.6\% in Cameroon (Halle-Ekane, Emade, Bechem, Palle, Fongaing, Essome, \& Fomulu,(2016). and even the $15.8 \%$ in Ghana as indicated by Owiredu et al. (2016).

The current study finding was comparatively lower than the range of $17.8 \%-26.3 \%$ PPH prevalence rates across America, Asia, Australia, and Europe (Fan et al., 2017). Also, in another study in Pakistan, the $21.3 \%$ prevalence rate was still three times higher than the result of this current study (Gani \& Ali, 2013). Gani \& Ali (2013) attribute the difference in their prevalence rate to the lack of access to health facilities. However, the women in the current study had access to primary health care services such as pregnancy and delivery services through community-based health planning and services, this could have improved delivery services for these women in the study, reducing $\mathrm{PPH}$.

The essential nutrition indicators in the study that were found to have influenced the likelihood of mothers experiencing PPH included iron-Folic Acid (IFA) supplementation. Mothers who 
received IFA supplementation in the study had a reduced risk of PPH. Having a reduced risk of PPH may be related to the reduction in anaemia status among the mothers, from $52.5 \%$ of anaemia at ANC registration to $37.7 \%$ at 36 weeks in pregnancy. Anaemia has been found to be a risk factor to PPH (World Health Organization, 2011). A related study has shown that even though intermittent supplementation was shown to have improved iron status more than no supplementation, a systematic review of the research proved that women receiving daily iron supplements tended to have lower haemoglobin and ferritin concentrations. They were equally likely to be anaemic as those receiving intermittent iron supplements (World Health Organization, 2011).

The results in the current study could have been consolidated by the fact that the mothers with normal $\mathrm{Hb}$ levels were also at a lower risk of PPH in the current study. An Indian study also revealed that nutrition and health education and IFA supplementation were a positive means of improving mothers' health and nutrition status, together with eradicating anaemia. The study showed that mothers who received IFA supplementation and nutrition education reduced anaemia prevalence from $53.8 \%$ to $39 \%$ (Monica, 2015), similar to the current study's finding. Again, health education and IFA supplementation have proven to improve significantly (Sen \& Kanani, 2012; Bissu, Singh \& Chishty, 2015). Contrary to this finding, an RCT of preconception supplementation IFA in Vietnam demonstrated no impact on the prevalence of anaemia or mean haemoglobin concentrations during pregnancy or postpartum (Nguyen, Young, Gonzalez-Casanova, Pham, Nguyen, Truong, Nguyen, Harding, Reinhart, Martorell, \& Ramakrishnan, 2016). However, further studies are required to evaluate the significant impact of IFA supplementation on maternal PPH status.

Generally, malnourished mothers in the study were those with BMI scores outside the range of 18.49$24.49 \mathrm{~kg} / \mathrm{m}^{2}$. Malnourished mothers at ANC registration with BMI scores outside this specified range were equally predisposed to $\mathrm{PPH}$ as the well- nourished mothers in the current study. Contrarily, BMI greater than $30 \mathrm{~kg} / \mathrm{m}^{2}$ of women before the third month of pregnancy was strongly associated with PPH among Indian women (Deshmukh, Jadhav \& Yelikar, 2016). However, at 36weeks of pregnancy, well-nourished mothers had a reduced risk of PPH. The latter could probably be attributed to the general nutrition counselling services and the mothers' other services when they contacted the ANC clinic from pregnancy to delivery. Comparatively, in New Zealand, Fyfe et al. (2012) specifically found that overweight and obesity were both risk factors for PPH. Obesity mainly had a twofold increase in risk for PPH than nulliparous. Maternal demographic characteristics such as age groupings (smaller age groupings) and height were significant risk factors to PPH. Lower maternal age and height pre-signify poor maternal growth and development before conception. The findings suggest that some of the mothers in the study were not biologically mature and nutritionally balanced to cater to fetal and maternal health needs during pregnancy. This challenge was probably the reflection when mothers with multiple pregnancies had a reduced risk of PPH than primed mothers. Perhaps, this could be attributed primarily to the age of mothers, which is young in the study population. Then again, mothers of infants with lower Apgar scores of less than ten were also predisposed to PPH. Apgar score is also used to predict maternal and child health conditions and access to health services (World Health Organization, 2011).

\section{Conclusion}

Although the prevalence of postpartum haemorrhage is relatively minor, the effects of poor nutrition on excessive maternal bleeding cannot be underestimated. Improving maternal nutrition such as IFA supplementation, $\mathrm{Hb}$ level, and BMI together with adequate maternal height before delivery will by far reduce the chances of bleeding during delivery and possibly improve all birth outcomes as a whole. Policymakers need to develop nutrition-specific interventions for mothers before and during pregnancy. 


\section{References}

Abu-saad, K., \& Fraser, D. (2010). Maternal nutrition and birth outcomes, 32, 5-25.

Ashigbie, P. (2013). Background paper 6.16 postpartum haemorrhage. Priority medicines for Europe and the World "A public health approach to innovation". https://www.who.int/medicines/areas/priority medicines/BP6_19Rare.pdf

Bissu, M., Singh, N., \& Chishty, S. (2015). Impact of IFA supplementation, health and nutrition education in improvement of nutritional and health status of Saharia women of Baran District. International journal of innovation and review ISSN. 3(3). 62-68

Bonnet, M. P., \& Benhamfou, D. (2016). Management of postpartum haemorrhage [version 1; referees: 2 aproved]. F100Resarch. F100 Faculty Reviews. 5(1514), 1 https://www.ncbi.nlm.nih.gov/pmc/articles/P MC4926727/pdf/f1000research-5-8435.pdf

Calvert, C., Thomas, S. L., Ronsmans, C., Wagner, K. S., Adler, A. J., \& Filippi, V. (2012). Identifying regional variation in the prevalence of postpartum haemorrhage: A systematic review and meta-analysis. PLOS ONE, 7(7). https://doi.org/10.1371/journal.pone.0041114

Cetin, I. \& Laoreti, A. (2015). The importance of maternal nutrition for health. Edition; Fanos, V., Mussap, M., Del Vecchio, A., Sun, B., Boomsma, D. I., Faa, G., and Giordano, A. Journal of pediatric and neonatal individualized medicine. 4(2) doi: $10.7363 / 040220$

Collins, P. W. Bell, S. F., de Lloyd L. \& Collins, R. E (2019). Management of postpartum haemorrhage: from research into practice, a narrative review of the lietrature and the Cardiff experience. International journal of obstetric anesthesia. 37. 106-117. https://www.sciencedirect.com/science/article/ pii/S0959289X18301821
Der, E. M., Moyer, C., Gyasi, R. K., Akosa, A. B., Tettey, Y., Akakpo, P. K., Blankson, A \& Anim, J. T. (2013). Pregnancy-related causes of deaths in Ghana: a 5-year retrospective study. Ghana Medical Journal, 47(4), 1.

District Profile, (2018). Annual performance review. Ghana Health Service, Lambussie. Upper West Regions, Ghana

Dsehmukh, V. L., Jadhav, M. \& Yelikar, K. (2016). Impact of high BMI of pregnancy: maternal and foetal outcome. Journal of obstetrics and gynaecology of India. 66(1). 192-197

Fan, D., Xia, Q., Liu, L., Wu, S., Tian, G., Wang, W., Wu, S., Guo, X., \& Liu, Z. (2017). The incidence of postpartum haemorrhage in pregnant women with placenta previa: A systematic review and meta-analysis. PLoS ONE, 12(1), 1-15. https://doi.org/10.1371/journal.pone.0170194

Frass, K. A. (2015). Postpartum haemorrhage is related to the haemoglobin levels at labour: an observational study. Alexandra journal of medicine, ELSEVIER. 51:333-337. http://dx.doi.org/10.1016/j.ajme.2014.12.002

Fyfe, E. M., Thompson, J. M., Anderson, N. H., Groom, K. M., \& McCowan, L. M. (2012). Maternal obesity and postpartum haemorrhage after vaginal and caesarean delivery among nulliparous women at term: a retrospective cohort study. BMC Pregnancy and Childbirth, 12(1), 112. https://doi.org/10.1186/1471-2393$\underline{12-112}$

Gani, N., \& Ali, T. S. (2013). Prevalence and factors associated with maternal postpartum haemorrhage in Khyber Agency, Pakistan. Journal of Ayub Medical College, Abbottabad: $J A M C, \quad 25, \quad 81-85$. Retrieved from http://ovidsp.ovid.com/ovidweb.cgi?T=JS\&C $\mathrm{SC}=\mathrm{Y} \& \mathrm{NEWS}=\mathrm{N} \& \mathrm{PAGE}=$ fulltext $\& \mathrm{D}=$ medl $\& \mathrm{AN}=25098062$

Halle-Ekane, G. E., Emade, F. K., Bechem, N. N., Palle, J. N., Fongaing, D., Essome, H., \& 
Fomulu N. (2016). Prevalence and Risk Factors of Primary Postpartum Hemorrhage after Vaginal Deliveries in the Bonassama District Hospital, Cameroon. International Journal of Tropical Disease \& Health, 13(2), 1-12. https://doi.org/10.9734/IJTDH/2016/23078

https://doi.org/10.1093/epirev/mxq001.

Kumar, N. (2016). Postpartum haemorrhage; a major killer of women: review of current scenario. Obstetrics \& Gynaecology International Journal. 4(4): 1-7. DOI: 10.15406/ogij.2016.04.00116

Meaney S., (2017). Experience of postpartum haemorrhage. National Perinatal Epidemiology Centre. ucc.ie/en/media/research/nationalperinatalepid emiologycentre/npecstudyday2016/MeaneyN PECStudy2017.pdf

Monica S.T., (2015). The association between iron supplementation during pregnancy and childhood and anaemia status among one to five-year-old children in India. School of Public Health, American University of Armenia Yerevan, Armenia. http://sph.aua.am/files/2017/07/Monica-SteffiThomas-2017.pdf

Motsi P., S. C. (2006). Influence of parity, birth order, litter size and birth weight on the duration of farrowing and birth intervals in commercial exotic sows in Zimbabwe. Cambridge University Press, 82(4), 569-574.

Mpemba, F., Kampo, S., \& Zhang, X. (2014). Towards 2015: Postpartum haemorrhage in sub-Saharan Africa is still on the rise. Journal of Clinical Nursing. https://doi.org/10.1111/jocn.12126

Nguyen, P. H., Young, M., Gonzalez-Casanova, I., Pham, H. Q., Nguyen, H., Truong, T. V., Nguyen, S. V., Harding, K. B., Reinhart, G. A., Martorell, R., \& Ramakrishnan, U. (2016). Impact of preception micronutrient supplementation on anaemia and iron status during pregnancy and postpartum: a randomized controlled trial in rural Vietnam. Open Access Journal. 11(12). https://www.ncbi.nlm.nih.gov/pmc/articles/P MC5137891/

NICE (2015). Maternal and child nutrition. Quality Standard. National Institute for Health and Care Excellence. www.nice.org.uk/guidance/qs98

Ononge, S., Mirembe, F., Wandabwa, J., \& Campbell, O. M. R. (2016). Incidence and risk factors for postpartum haemorrhage in Uganda. Reproductive Health, 13(1), 38. https://doi.org/10.1186/s12978-016-0154-8

Owiredu, W. K. B. A., Osakunor, D. N. M., Turpin, C. A, \& Owusu A. (2016). Laboratory prediction of primary postpartum haemorrhage: a comparative cohort study. BMC Pregnancy and Childbirth. doi: $\quad$ 10.1186/s12884-016-0805-3. https://www.ncbi.nlm.nih.gov/pmc/articles/P MC4727344/

Oyelese, Y., \& Ananth, C. V. (2010). Postpartum haemorrhage: epidemiology, risk factors, and causes. Clinical Obstetrics and Gynecology, 53(1), 147-156. https://doi.org/10.1097/GRF.0b013e3181cc40 $6 d$

Program for Appropriate Technology in Health [PATH]. (2014). Saving mothers' lives by preventing postpartum haemorrhage in Ghana. Advocacy impact case studies. 455 Massachusetts Ave NW, Suite 1000. Washington. DC 2001

Sen, A. \& Kanani, S. (2012). Intermittent Iron folate supplementation: impact on hematinic status and growth of school girls. International scholarly research network ISRN Hematology. 2012, 1-6. doi:10.5402/2012/482153 https://www.ncbi.nlm.nih.gov/pmc/articles/P MC3412096/pdf/ISRN.HEMATOLOGY2012 -482153.pdf 
Sheldon, W. R., Blum, J., Vogel, J. P., Souza, J. P. G€ulmezoglu, A. M. Winikoff, B. (2013). Postpartum haemorrhage management, risks, and maternal outcomes: findings from the World Health Organization Multicountry Survey on Maternal and Newborn Health. Original Article. WHO Multicountry Survey on Maternal and Newborn Health Research Network. Gynuity Health Projects, New York, NY, USA. DOI: 10.1111/1471-0528.12636

World Health Organization [WHO] (2016). Good maternal nutrition: the best start in life. World Health Organization. Regional Office for Europe. UN City, Marmorvej 51. DK-2100 Copenhagen, Denmark.
World Health Organization [WHO]. (2011). Evidence for Essential Nutrition Action [online]. World Health Organization. Available: who.int/nutrition/EB128_18_backgroundpaper 2_A_reviewofhealthinterventionswithaneffect onnutrition.pdf. Accessed: 22th October 2017.

World Health Organization [WHO]. (2012). WHO recommendations for the prevention and treatment of postpartum haemorrhage. $\mathrm{WHO}$ Library Cataloguing-in-Publication Data. https://apps.who.int/iris/bitstream/handle/1066 5/75411/9789241548502_eng.pdf;sequence $=1$ 